\title{
Concepts of Economic Growth for Financial Stability of the State
}

\author{
Bulat Gaynutdinov ${ }^{1}$ Aleksey Lebedev ${ }^{2}$ Elena Razumovskaya ${ }^{3,4, *}$
}

\author{
${ }^{1}$ JSC “Ural Instrument-Making Plant”, Yekaterinburg, Russia \\ ${ }^{2}$ Foundation for the Development of Competencies and Qualifications in the Ural Region, Yekaterinburg, Russia \\ ${ }^{3}$ Department of Finance, Money Circulation and Credit, Ural Federal University named after B.N. Yeltsin, \\ Yekaterinburg, Russia \\ ${ }^{4}$ Department of Finance, Money Circulation and Credit, Ural State University of Economics, Yekaterinburg, Russia \\ *Corresponding author. Email: rasumovskaya.pochta@gmail.com
}

\begin{abstract}
The article is devoted to the analysis of existing concepts of economic growth in the light of their influence on the condition of the state financial system. The authors show the reflection of financial indicators in fundamental macroeconomic functions and reconstruct many of them. The concept-based feasibility of the main growth indicators of the national economy can serve for practical studies and further - for extrapolation of scenarios used for regulating structural financial parameters of the financial system to ensure stability of the latter in real conditions of high volatility of the external market. A comparative analysis of the dynamics of macroeconomic and financial indicators of the Russian economy is carried out to identify trends in the socio-economic development of the Russian Federation. In view of high relevance of research on the sources of sustained economic growth, the main goal of the authors is to search for a fundamental conceptual justification of the possibilities of socio-economic development while maintaining stability of the country's financial system. The result of the study is a theoretical model design that reflects a combination of economic and financial parameters of national economy, whose regulation can ensure the growth of national economy under financial stability.
\end{abstract}

Keywords: economic growth, financial stability, financial system, macroeconomic dynamics

\section{INTRODUCTION}

The authors aim at analyzing modern concepts of economic growth to justify financial factors regulated by all countries of the world. The study should result in the formation of a viable model designed to reflect characteristics of the national economy of Russia. Besides, the authors are aware of the fact that practical application of most models in their original form is unattainable in reality.

Traditionally, the main task of fundamental scientific research in the field of economics and finance is to search for sources of economic growth. Building of theoretical models based on macroeconomic analysis allows us to proceed from traditional principles: the analysis of an array of empirical data provides reasonable arguments for identifying trends, tendencies and factors affecting the socio-economic development of economic systems.

The ongoing transformation of the institutions and infrastructure of the Russian national economy keeps up to date the research on approaches to assessing the impact of the internal market conditions, developing under the influence of geopolitical and global processes on the results of socio-economic development of the national economy [3]. The Russian economy even in market conditions retains its peculiarity - a high degree of state responsibility for social consequences of ongoing transformations, realized through redistribution of financing of individual regions and industries, based on national interests. That is why the main engines of Russia's economic growth are nationwide programs in three key areas:

1) Building and preservation of human capital, which involves financing of health care, education, culture and demography, stimulating fertility and increasing life expectancy of the population.

2) Comfortable living environment for the population of the Russian Federation, providing funding to construct safe and high-quality roads, accommodation and urban infrastructure; to improve environmental conditions in the regions.

3) Stimulating economic growth through creation of high technology; support for small and medium enterprises; increase of labor productivity; international cooperation and export; modernization of national economy and development of digital environment in the real and financial sectors.

\section{MODELING}

Building of conceptual designs of economic growth presupposes inevitable model assumptions, which may not be fully correlated with real economic conditions. In addition, when modeling factors affecting economic growth 
and assessing the degree of this influence, the authors propose to take into account conditions of Russian economy and those prospects that are realistically achievable. The author's choice of neo-Keynesian and neoclassical theories as a modeling platform in this study is due to the following reasons:

1. Neo-Keynesian concepts are based not only on the fundamental admissibility of state regulation of the economy, but they also consider it necessary during periods of economic remission. The neo-Keynesian message coincides with the Russian policy in the field of socioeconomic development by methods of direct regulation of regions and industries.

2. Neo-Keynesian concepts are based on the need to conduct a dynamic analysis of the conditions of full employment and ensure the potential economic growth due to the maximum load of production capacities. Attainability of such a situation, even exclusively in the long run, is possible only with a very significant reduction in the financing of the current needs of society and investing in advanced technologies.

3. The neo-classical concepts are based on the analysis of significant volumes of empirical data, allowing research and building of forecast scenarios of macroeconomic dynamics; the exogenous scientific and technological progress is considered by the neo-classics as the source of economic growth - that is, financing of advanced technologies [4].

The specified characteristics of neo-Keynesian and neoclassical concepts make it possible to model the results of socio-economic development of the Russian economy. However, the authors understand that possibilities for practical application of modeling results are limited due to relatively specialized methodological tools, which presuppose mainly the decomposition of reproduction processes and contribution of individual structural factors of production to the growth (increase) of the total output.

It is probable that theoretical modeling may not be enough in the context of urgent tasks of creating financial stability to stimulate positive macroeconomic dynamics, however, an attempt of such modeling can be implemented in a scenario format providing additions and adaptations that actualize the model for real-world market conditions. The values of neo-Keynesian and neoclassical concepts are suitable to search for a justification for the trajectories of socio-economic development, considering the financial system characteristics. Moreover, they can be used in interpreting patterns and predicting certain assumptions in certain limited conditions. The scientific value of scenario models is due to their fundamental nature and analytical potential. The authors are not inclined to overestimate practical significance of the expected results, since in relation to the rapid dynamics of a not quite stable financial and economic system, it is extremely difficult to create a model of its sustainable development [3]. At the same time, the same reasons make it necessary to apply state regulation as a flexible method of responding to changes in the external environment.
Without aiming to solve fundamental theoretical problems in the field of financial science, the authors do not claim to be extremely unique in the proposed scenario model of economic growth for the domestic national economy as a guide to action for the authorities. On the contrary, in the research interests, the model should be unified in nature, taking into account the features of the ongoing transitional stage experienced by the Russian economic system. The authors also seek to politicize the study in view of a simple conviction: the difficulties encountered in the domestic financial and economic system may be random in nature, due to external factors, regardless of specific personalities. The solutions to certain problems are really obvious to everyone only after some wrong or not suitable for everyone solutions have been found. However, one has to take the very unpopular or even erroneous measures in conditions of ignorance of their consequences - and this is the very responsibility that no one wants to take.

At the end of the preliminary modeling stage, the authors note that the basic parameters, which are usually relied upon - gross domestic product, level of labor productivity, investment values and possibility of their dynamics, seem to be insufficient. It is absolutely necessary to supplement this list with the volumes and, possibly, rates of capital outflow, influence of inflation, the size of disposable incomes of the population and the number of potential employees, which will help to create a more viable model. Universal models of economic growth are the most common [1], because they can be suitable for all types of economic systems and for a wide variety of market conditions. The latter are the same for all countries and do not take into account differences in the level of development of the financial system and the real sector, using statistical methods to process the quantitative parameters of the economies under study. At the same time, the analysis of empirical data reveals the catalysts and constraining factors of economic growth, which are the basic reasons for increasing polarization and heterogeneity of the world economy [2].

This study is aimed at analyzing theoretical concepts of macroeconomic dynamics from the perspective of assessing the potential need for government regulation of national economy and its financial system in order to ensure stability of the latter. This message is due to the exclusion of excessive complexity of computational tools in order to avoid criticism regarding validity of the use of nonindisputable, from the methodological point of view, tools. It is unpromising to dispute significant differences in the financial, legal, organizational, administrative and many other conditions for doing business in the prevailing stable and still emerging market economies, however, it is quite advisable to try to create some kind of unified design that can describe financial and economic processes to predict trends in their development, suggesting the possibility of applying scenario adjustments.

The concepts of economic growth, for the most part, are not unreasonably based on a quantitative analysis of 'input / output' combination, which forms the basis of the neoKeynesian design (equation 1): 
$\Delta \mathrm{Y}=\mathrm{Y}_{\mathrm{t}}-\mathrm{Y}_{\mathrm{t}-1}=\mathrm{A} \times\left(\mathrm{K}_{\mathrm{t}}-\mathrm{K}_{\mathrm{t}-1}\right)=\mathrm{A} \times \Delta \mathrm{K}=\mathrm{A} \times \mathrm{I}$

where $\mathrm{Y}$ is output in the national economy;

A is marginal productivity of capital;

$\mathrm{K}$ is capital input;

I is the amount of available investments.

Feasibility of this combination is undeniable, because it reflects the impact on the volume of capital productivity output - a financial parameter, the economic meaning of which is the limit of potentially available investments in the analyzed economic system. Provision of the economy with production factors and, first of all, with financial resources is the key to its ongoing development. Inclusion of the capital factor is not just traditional for modeling, it is becoming more important in modern processes for the production of final products. The functional design itself demonstrates the unity of combinativity of financial resources for the economies of all countries of the world, putting in the first place the determinate 'quality' of the capital factor.

It is quite obvious that the most well-known concepts of economic growth, and among them the Harrod-Domar theory, are designed to solve the problems of finding, generalizing and systematizing the equilibrium conditions for the economic system, under which the produced product is completely consumed within the economy and the excess is exported, which reflects Keynesian premise. Moreover, none of the concepts provides creation of an isolated or unique theory of the market economy growth [5]. It is a completely different matter to maintain financial stability, which is difficult to achieve for countries with a transitional heritage, which are forced to resort to excessive monetary stimulation of the growth rates of their economies.

The analysis is complicated by the fact that real economic systems are in the process of continuous development, regardless of the amplitude and pace of the latter, and therefore cannot be analyzed using static methods. The reality is that production capabilities are constantly changing under the influence of a wide range of factors, which leads to a change in the volume of goods produced, for which there is quite stable and often growing consumer demand [8]. The inevitable dynamism of the 'input / output' design allows us to argue that creation of stable factor conditions for the ongoing economic development is practically unrealizable.

Adoption of this assumption actualizes the following question: is it possible to achieve a format for the functioning of an economic system where, over long periods of time, it is possible to simultaneously change the volumes of production factors that provide aggregate output and aggregate demand? The answer lies in mathematical modeling methods: using the Keynesian multiplier, we obtain the following equation:

$$
\Delta \mathrm{Y}=\mathrm{Y}_{\mathrm{t}}-\mathrm{Y}_{\mathrm{t}-1}=\mathrm{k}_{\mu} \times \Delta \mathrm{I}
$$

The Keynes multiplier ( $k_{\mu}$ factor) was calculated by a wellknown method using marginal propensities to consume and save, which for the purposes of the conducted modelling can be taken as constants. These most important indicators of the financial behavior of population form the entire neoKeynesian analysis in terms of macroeconomic parameters. The final form of the function, providing conditions for the functioning of economy in a state of constant full employment is as follows:

$$
\mathrm{A} \times \mathrm{I}=\mathrm{k}_{\mu} \times \Delta \mathrm{I},
$$

or can be presented as another equation:

$$
\Delta \mathrm{I} / \mathrm{I}=\mathrm{A} \times \mathrm{k}_{\mu}
$$

What do the obtained functions give for the purposes of this modelling? The answer is obvious: the development of all national economies (regardless of the level of development of market relations in them) at a steady pace is due to the need to synchronize the pace of investment dynamics and output [7]. This statement should not be interpreted in such a way that a $1 \%$ increase in investments should lead to an increase in output by the same amount - it would be simply ridiculous. In this context, we are talking about maintaining a constant pace of dynamics, mathematically defined as the product of the marginal productivity of capital and the marginal propensity to save (equation 5):

$$
\Delta \mathrm{I} / \mathrm{I}=\Delta \mathrm{Y} / \mathrm{Y}=\Delta \mathrm{AS} / \mathrm{AS}=\mathrm{A} \times \mathrm{k}_{\mu}
$$

where AS is the value of aggregate supply in the national economy.

The authors understand that the presented modelling is not completely unique from the point of view of its origin, however, they proceeded from the detailed substantiation of the shown calculations, and relied upon fundamental theories recognized in the world and relevant to the present day.

It is much more important that the result obtained is realistic from the standpoint of its adequacy and can be verified by the following numerical example: let the marginal propensity for saving (mps) in the Russian economy be $0.08 \%$; and the share of capital in national income be $22-24 \%$. This means that with such initial data, the national economy can in practice grow at the following pace:

$$
\Delta \mathrm{Y} / \mathrm{Y}=0.08 \times 0.23=1.84 \%
$$

\section{RESULTS}

The obtained result, according to the authors, corresponds to the realities of the Russian economy indeed, the Ministry of Economic Development and the Central Bank of the Russian Federation announced that the growth rate of the domestic economy in 2019 was about $1.8 \%$. However, the main thing testified by the result is a consistent reduction of the rate by the Central Bank, which ensures loosening of monetary policy under the conditions of tightening of budget policy. It was this measure, according to the authors, that made it possible to prevent a reduction in output and provided stable 
Economic Development, Financial Economics, 2019, No. 7. - pp. 279 - 282.

[4] Razumovskaya Ye.A., Lebedev A.V. Theoretical Aspects of Modeling the Results of Socio-Economic Development of the National Economy of Russia, Bulletin of SSEU, No. 4 (174) 2019. - pp. 20 - 28.

[5] Harrod R. Toward a Theory of Economic Dynamics. Translated by I.K. Dashkovsky edited by Yu.Ya. Olsevich. M. Publishing House of Foreign Literature, 1959. - $211 \mathrm{p}$.

[6] Official site of the Federal State Statistics Service, Electronic resource. Reference date 07/01/2019: FSSS http://www.gks.ru/wps/wcm/connect/rosstat_main/rosst at/ru/statistics/accounts/\#

[7] Cournède B., Denk O. Finance and Economic Growth in OECD and G20 Countries. OECD Economics Department Working Papers, 2015, no. 1223, Electronic resource. Reference date 11.10.2019. https://econpapers.repec.org/paper/oececoaaa/1223en.html

[8] Fîrcescua B., Crises Effects on Financial System Structure in some Post-Communist Countries, Procedia: Social and Behavioral Sciences. Volume 5812, October, 2012, pp. $444-453$. 